\title{
BASIC PHARMACOLOGY
}

\section{The mTOR/p70 ${ }^{S 6 \mathrm{~K}}$ Signal Transduction Pathway Plays a Role in Cardiac Hypertrophy and Influences Expression of Myosin Heavy Chain Genes in vivo}

Marvin O. Boluyt, Zhao Bo Li, Amy M. Loyd, Antony F. Scalia, Georgina M. Cirrincione, and Rebecca R. Jackson

Laboratory of Molecular Kinesiology, The University of Michigan, Ann Arbor, MI 48109-2214, USA Supported by the Michigan and Midwest Affiliates of the American Heart Association.

\begin{abstract}
Summary. Objective: Rapamycin (R) inhibits p70 S6 kinase $\left(\mathrm{p}^{\mathrm{S}} 0^{\mathrm{S} 6 \mathrm{~K}}\right)$ activity and hypertrophy of cultured neonatal rat cardiac myocytes. The purpose of the present study was to determine whether rapamycin inhibits left ventricular (L V) hypertrophy in intact rats and whether it alters cardiac gene expression.

Methods: $300 \mathrm{~g}$ rats were subjected to aortic constriction (AC) or sham-operation (SH) and studied 2 and 3 days after surgery. Beginning 1 day prior to surgery, rats were injected with rapamycin $(1.5 \mathrm{mg} / \mathrm{kg}$, i.p.) or carboxymethylcellulose vehicle (V), yielding 4 groups (SH-V, SH-R, AC-V, AC-R). Total RNA was extracted for determination of mRNA levels by Northern blotting.

Results: LV dry weight/body weight ratios were $0.43 \pm 0.04$ (mean \pm SE) for SH-V, $0.46 \pm 0.02$ for SH-R $0.56 \pm 0.02$ for $\mathrm{AC}-\mathrm{V}$, and $0.53 \pm 0.03$ for AC-R. $\mathrm{R}$ inhibited cardiac hypertrophy induced by pressure overload (ANOVA; $p<0.05)$. Rapamycin had no effect on the expression of atrial natriuretic factor mRNA, but increased the levels of $\beta$-myosin heavy chain mRNA 6-fold in hearts of SH-R and AC-R compared to SH-V. Rapamycin also increased the expression of $\alpha$-myosin heavy chain mRNA in SH-R by 3 -fold compared with SH-V, but had no effect on the AC-R group.

Conclusion: The data suggest that an intact mTOR signaling pathway is required for rapid hypertrophic growth of the heart in vivo. Moreover, the data suggest a novel link between the $\mathrm{mTOR} / \mathrm{p}^{\mathrm{S}}{ }^{\mathrm{S} 6 \mathrm{~K}}$ signal transduction pathway and pretranslational control of myosin gene expression in the heart.
\end{abstract}

Key Words. pressure overload, cardiac hypertrophy, immunosuppressant, myosin heavy chain, rapamycin, signal transduction, translational regulation

\section{Introduction}

Cardiac myocyte hypertrophy requires increased synthesis of cellular protein involving both transcriptional and translational mechanisms [1-4]. Control of these processes is exerted by a web of intracellular signaling pathways consisting of kinases and other molecules that act to upregulate or downregulate transcription of specific genes and to modulate translation of various classes of mRNA. The mTOR/p $70^{\mathrm{S} 6 \mathrm{~K}}$ signal transduction pathway is an important and ubiquitous regulator of cell size [5]. In drosophila, loss of dS6K function (the homologue of mammalian $\mathrm{p} 70^{\mathrm{S} 6 \mathrm{~K}}$ ) results in flies with smaller cells, but no decrease in cell number [6]. In rodent skeletal muscle, $\mathrm{mTOR} / \mathrm{p} 70^{\mathrm{S} 6 \mathrm{~K}}$ signaling plays a critical role in load-induced growth $[7,8]$. The $\mathrm{mTOR} / \mathrm{p} 70^{\mathrm{S} 6 \mathrm{~K}}$ pathway regulates translational aspects of protein synthesis and is required for hypertrophy of cultured neonatal rat cardiac myocytes $[9,10]$. In vivo, $\mathrm{p} 70^{\mathrm{S} 6 \mathrm{~K}}$ is activated by pulmonary artery constriction in the feline right ventricle and correlates with the hypertrophic growth of that ventricle [11]. When the current studies were begun, the precise role of the $\mathrm{mTOR} / \mathrm{p} 70^{\mathrm{S} 6 \mathrm{~K}}$ signaling pathway in pressure overload-induced cardiac hypertrophy in vivo had not been established.

Evidence suggests that phosphorylation of the ribosomal S6 protein regulates the translation of mRNAs into proteins. The ribosomal S6 protein is uniquely positioned to regulate the protein synthetic machinery from its location at the tRNA-mRNA-binding site of the 40S ribosome [12]. It appears to play a role in the activation of protein synthesis and to regulate the overall rate of translation [13]. The ribosomal S6 protein is phosphorylated on a number of residues by $p 70^{\mathrm{S} 6 \mathrm{~K}}[13,14]$. Phosphorylation of these residues results in an increase in the rate of serum-stimulated protein synthesis and a selective increase in the translation of mRNAs containing a polypyrimidine tract at the 5 ' terminus [13]. This class of mRNAs includes those encoding ribosomal proteins and proteins involved in the initiation of translation [15]. Thus, selective accumulation of these proteins that constitute the translational machinery is

Address for correspondence: Marvin O. Boluyt, Ph.D., The University of Michigan, Laboratory of Molecular Kinesiology, 401 Washtenaw Avenue, Ann Arbor, MI 48109-2214, USA. Tel.: (734) 647-7645; Fax: (734) 936-1925; E-mail: boluytm@umich.edu 
thought to lead to a general increase in the rate of translation.

Rapamycin is an immunosuppressive macrolide that inhibits $\mathrm{p} 70^{\mathrm{S} 6 \mathrm{~K}}$ activity in fibroblast cells and limits the rate at which fibroblast cells and T-lymphocytes enter S phase $[14,16]$. The effects of rapamycin are mediated through its binding to FK506 binding protein (FKBP), an intracellular immunophilin known to bind FK506 [17-19]. Inhibition of $\mathrm{p} 70^{\mathrm{S} 6 \mathrm{~K}}$ activity by rapamycin in fibroblasts is accompanied by inhibition of protein synthesis and selective repression of the translation of "polypyrimidine tract" mRNAs that encode elongation factors and ribosomal proteins [13,20,21]. Selective regulation of this class of mRNAs may be particularly relevant in cardiac myocytes, because an important early event in the hypertrophic growth of the heart is an accumulation of ribosomal subunits [22,23].

The goals of this study were to determine whether signaling via the $\mathrm{mTOR} / \mathrm{p} 70^{\mathrm{S} 6 \mathrm{~K}}$ pathway is required for cardiac hypertrophy in the intact rat and whether signaling via this pathway influences expression of hypertrophy-associated genes. To address this issue, growth of the heart stimulated by aortic constriction in rats that were treated with either rapamycin or vehicle was compared. The results indicate that rapamycin inhibits activation of $\mathrm{p} 70^{\mathrm{S} 6 \mathrm{~K}}$ and attenuates hypertrophic growth of the rat heart after aortic constriction. The data also suggest a novel link between the $\mathrm{mTOR} / \mathrm{p} 70^{\mathrm{S} 6 \mathrm{~K}}$ signal transduction pathway and pretranslational control of myosin gene expression in the heart.

\section{Methods}

Materials. Rapamycin was a generous gift of WyethAyerst (Princeton, NJ). The carboxymethylcellulose vehicle was obtained from Sigma (St. Louis, MO). Hemoclips were from Weck (Research Triangle Park, $\mathrm{NC})$. Antibodies directed at $\mathrm{p} 70^{\mathrm{S} 6 \mathrm{~K}}$ were from Santa Cruz Biotechnology (Santa Cruz, CA). Secondary antibodies, enhanced chemiluminescent (ECL) detection reagents, and radioactively labeled nucleotides were purchased from Amersham (Arlington Heights, IL). Reagents and consumables were purchased from Fisher Scientific (Hampton, NH) unless otherwise stated.

Animals. Six-week old male Sprague-Dawley rats weighing 225-250 g were obtained from Charles River Laboratories (Wilmington, MA) and maintained on a 12h:12h light:dark cycle with rat chow and water ad libitum. All animal protocols were approved by the University Committee on Use and Care of Animals at the University of Michigan. The investigation conforms with the Guide for the Care and Use of Laboratory Animals published by the US National Institutes of Health (NIH Publication No. 85-23, revised in 1996). Rats were initially assigned to either sham-operation (SH) or aortic constriction (AC) groups.
Aortic constriction. AC was performed as described previously when rats weighed $300 \pm 10 \mathrm{~g}$ and were approximately 2 mo old [24]. Briefly, a left thoracotomy was performed under ketamine $(87 \mathrm{mg} / \mathrm{kg})$ and pentobarbital $(30 \mathrm{mg} / \mathrm{kg})$ anesthesia and the ascending aorta was exposed. A Weck hemoclip was placed around the aorta 4-6 $\mathrm{mm}$ superior to the aortic valve with the gap of the Weck hemoclip applicator adjusted to 1.02 mm by a thumbscrew. Preliminary experiments established that a left ventricle/distal aorta pressure gradient of $46 \pm 12 \mathrm{mmHg}$ resulted from constriction of the severity imposed by the $1.02 \mathrm{~mm}$ setting. A catheter linked to a pressure transducer was inserted into the carotid artery. With the catheter in place, the aortic band was applied, and the acute increase in pressure was recorded. In "dose-response" experiments, the gap of the hemoclip applicator was adjusted to increase or decrease the severity of constriction. When the clip was in place, pleural pressure was reinstated and the wound closed with a silk suture. At designated times after AC, the left ventricles were quickly dissected free, weighed and rapidly frozen by clamping with tongs cooled to the temperature of liquid nitrogen. Tissues were stored at $-70^{\circ} \mathrm{C}$ for subsequent analysis.

Rapamycin treatment. Rapamycin was given at a dose of $1.5 \mathrm{mg} / \mathrm{kg}$ body weight by injection into the intraperitoneal cavity. Preliminary experiments had determined that inhibition of aortic-constriction-induced cardiac hypertrophy was maximized with a dose of either $0.75 \mathrm{mg} / \mathrm{kg}$ or $1.5 \mathrm{mg} / \mathrm{kg}$. Carboxymethylcellulose $(0.2 \%)$ was used as the vehicle.

Immunoblotting and estimation of p\%o activity. Frozen heart tissue was homogenized in buffer $(62.5$ $\mathrm{mmol} / \mathrm{L}$, Tris, $\mathrm{pH} 6.8,1 \mathrm{mmol} / \mathrm{L}$ sodium orthovanadate, $10 \mathrm{nmol} / \mathrm{L}$ okadaic acid, $10 \mu \mathrm{g} / \mathrm{mL}$ leupeptin, and $10 \mu \mathrm{g} / \mathrm{mL}$ aprotinin). Homogenates were diluted with buffer to achieve the desired protein concentration and then mixed 1:1 with $2 \mathrm{X}$ sample buffer $(125 \mathrm{mmol} / \mathrm{L}$ Tris, pH 6.8, 4\% SDS, 20\% Glycerol, 10\% 2-mercaptoethanol, $0.001 \%$ bromphenol blue). $10-40 \mu \mathrm{g}$ of protein were loaded into each lane of a 7.5\% SDS-polyacrylamide gel and size fractionated by electrophoresis at a constant current of $20 \mathrm{~mA}$ for 16-20 hours. Proteins were then electrophoretically transferred to polyvinylidene difluoride (PVDF) membranes at 5V/cm for 16-20 hours at $4{ }^{\circ} \mathrm{C}$. After incubation in blocking solution (PBS-T, $1 \%$ bovine serum albumin) for 2 hours, membranes were washed three times in Western buffer $(50 \mathrm{mmol} / \mathrm{L} \mathrm{NaCl}$, $10 \mathrm{mmol} / \mathrm{L}$ Tris, pH 7.0, $1 \mathrm{mmol} / \mathrm{L}$ EDTA, 0.1\% Tween20 ) before incubation with the primary antibody (rabbit anti-p70 ${ }^{\mathrm{S} 6 \mathrm{~K}}$, C-18) for 16-20 hours, followed by three more washes and incubation for one hour with a 1:10,000 dilution of the secondary antibody (goat anti-rabbit IgG conjugated with horseradish peroxidase). Antibody binding was detected using the enhanced chemiluminescence (ECL) method according to the manufacturer's instructions.

In vitro $p \% 0^{S 6 K}$ assay. For a subset of hearts, a small portion of the LV was homogenized as above and used 
for an in vitro assay of immunoprecipitated $\mathrm{p} 70^{\mathrm{S} 6 \mathrm{~K}} \mathrm{ac}-$ tivity exactly as described previously [10].

$R N A$ isolation and determination of RNA yield. RNA was isolated from a pre-weighed portion of the left ventricle as described previously [25]. The resulting RNA pellet was dissolved in nuclease-free water. The concentration of the final RNA solution was determined at a wavelength of $260 \mathrm{~nm}$ with a Spectronic Instruments Genesys 5 spectrophotometer (Rochester, NY).

RNA blotting RNA blotting was performed as described previously with modifications [25]. Ten $\mu \mathrm{g}$ of total RNA was size fractionated by electrophoresis through $1 \%$ agarose gels, transferred electrophoretically at $5 \mathrm{~V} / \mathrm{cm}$ to a nylon (Nytran-SPC) membrane and hybridized with ${ }^{32} \mathrm{P}$-radiolabelled probes overnight at $68^{\circ} \mathrm{C}$ for cDNA probes and $42^{\circ} \mathrm{C}$ for oligonucleotide probes using PerfectHyb Plus (Sigma). Hybridization intensity was quantified with a Personal Phosphoimager FX (Bio-Rad, Hercules, CA). Signals visualized on computer screen were identified by position relative to $18 \mathrm{~S}$ and $28 \mathrm{~S}$ rRNA migration, delineated by rectangles, and quantified after background subtraction. Each blot was subsequently stripped, verified to be free of radioactivity, and reprobed. The relative amount of each message was calculated by first normalizing the signal to that of an oligonucleotide probe specific for the $18 \mathrm{~S}$ ribosomal RNA and then multiplying by the yield of total RNA per gram of tissue. Assuming that greater than $97 \%$ of the total RNA is ribosomal, this calculation gives an estimate of the mRNA abundance per gram heart tissue and is independent of other messages that may or may not be affected by the experimental treatments. In preliminary experiments, the signal from each sample was also normalized to the signal obtained with an oligonucleotide specific for the 3 ' untranslated region of glyceraldehyde-3-phosphate dehydrogenase (GAPDH), and one for $\beta$-actin. Based on those observations, normalization to levels of GAPDH mRNA produced the smallest error relative to the tissue adjusted values reported in Figures 4 and 5, while normalization to $\beta$-actin mRNA yielded extremely large errors, primarily because the levels of $\beta$-actin mRNA per gram tissue were markedly increased by aortic constriction (data not shown). All the mRNA values reported in this paper are expressed in relative amounts per gram tissue, using the 18S normalized value and adjusting for $\mathrm{RNA}$ yield. Interpretations are not altered if mRNA values are expressed relative to GAPDH.

Probes. Complementary DNA probes were synthesized from a template by the random prime method as described previously [25]. The templates for the atrial natriuretic factor (ANF) probe, the skeletal $\alpha$-actin, the cardiac $\alpha$-actin probes, were described previously [25]. The probes for $\alpha$-myosin heavy chain ( $\alpha$-MHC), $\beta$-myosin heavy chain ( $\beta$-MHC), and the $18 \mathrm{~S}$ ribosomal RNA were end-labeled synthetic oligonucleotides described previously [25]. The probe for c-fos was an $\approx 500$ base pair riboprobe described previously [26]. The probe for HSP70 was a cDNA described previously [27]. The probe for $\beta$-actin was a 40 base pair synthetic oligonucleotide complementary to a portion of the 3 'untranslated region with the sequence: 5' CGC AAG TTA GGT TTT GTC AAA GAA AGG GTG TAA AAC GCA G-3'. The probe for GAPDH was a 40 base pair synthetic oligonucleotide complementary to a portion of the 3'-untranslated region with the sequence: 5'CTC TTG CTC TCA GTA TCC TTG CTG GGC TGG GTG GTC CAG G-3'.

Cell culture and transfection. Neonatal cardiac myocytes were isolated and cultured as described previously [10] except that pre-plating for 30 min was used instead of a Percoll gradient to purify myocytes. Myocyte purity was at least $90 \%$ as determined by immunostaining of sarcomeric actin. Myocytes were transfected with a $-3542 /+85 \beta$-MHC-luciferase reporter construct (a generous gift from John Edwards) using a modified calcium phosphate method described previously [28]. Cells were co-transfected with a cytomegalovirus promoter-renilla reporter construct (Promega) to control for transfection efficiency. Cells were harvested and processed for a dual-luciferase assay (Promega).

Statistics. Values are expressed as mean \pm standard error of the mean (SE). Data were evaluated with a 3factor ANOVA procedure for all variables that were measured at 2 time points. A 2-factor ANOVA procedure was used for variables that were evaluated at a single time point. A one-tailed test was used to evaluate the Pearson correlation coefficient of the relationship between severity of constriction and phosphorylation of $\mathrm{p} 70^{\mathrm{S} 6 \mathrm{~K}}$. Differences were considered significant when $p<0.05$.

\section{Results}

Characterization of the hypertrophy model. To examine the effects of rapamycin on heart growth in vivo, aortic constriction, a commonly used model of rapid cardiac growth, was used. Aortic constriction of $300 \mathrm{~g}$ rats with a Weck hemoclip applicator gap set at $1.02 \mathrm{~mm}$ produced a pressure differential of $46 \pm 12 \mathrm{mmHg}$ and an $18 \%$ increase in LV dry weight by day 2 with evidence of a plateau by day 3 (Fig. 1). Consistent with previous reports [29-31], aortic constriction induced a pattern of gene expression that included rapid transient activation of c-fos and hsp70, and a delayed, more sustained activation of $\mathrm{ANF}$ and $\beta$-MHC (data not shown). Expression of cardiac $\alpha$-actin was unchanged, while that of skeletal $\alpha$-actin mRNA increased. A marked decrease in the level of $\alpha$-MHC mRNA was also observed (data not shown).

Dose-response effects of aortic constriction on $p \% 0^{\mathrm{S} 6 \mathrm{~K}}$ activity. It was reasoned that if the $\mathrm{mTOR} / \mathrm{p} 70^{\mathrm{S} 6 \mathrm{~K}}$ signaling pathway played an important role in hypertrophic growth, the magnitude 


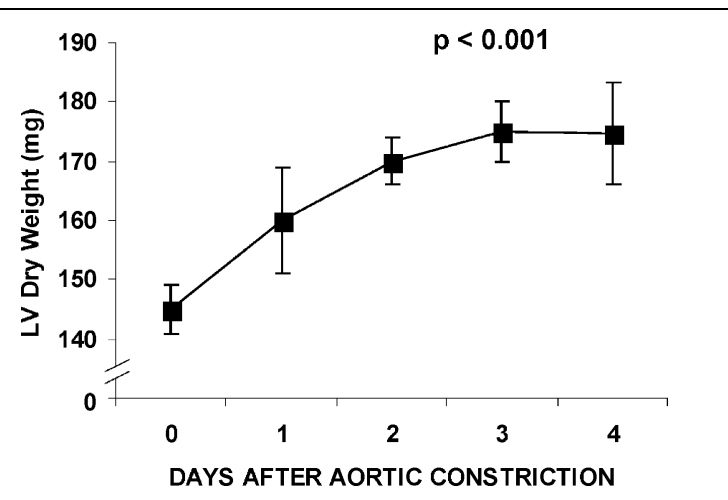

Fig. 1. Time course of cardiac hypertrophy after aortic constriction. Male Sprague-Dawley rats weighing $300 \pm 10 \mathrm{~g}$ were subjected to constriction of the ascending aorta and killed at the indicated times. LV dry weight increased 10\%, 17\%, 21\%, and $20 \%$ after 1, 2, 3, and 4 days of aortic constriction, respectively. The value for the overall one-way ANOVA is inset. $L V$ dry weight is significantly greater than control (day 0) at days 2 and 3 and 4 ( $p<0.05$, Fisher's LSD). LV, left ventricle including septum. Values are mean $\pm S E$ for $n=9,5,5,18$, and 3 rats at each time point from day 0 through day 4 , respectively.

of the increase in kinase activity should be related to the intensity of the growth stimulus. To determine the dose-response effects of aortic constriction on the $\mathrm{mTOR} / \mathrm{p} 70^{\mathrm{S} 6 \mathrm{~K}}$ signaling cascade, rats were subjected to aortic constriction of several different levels of severity. To do this, the Weck hemoclip applicator gap was set at $1.20 \mathrm{~mm}, 1.14 \mathrm{~mm}, 1.02 \mathrm{~mm}$, or $0.89 \mathrm{~mm}$. Activation of the mTOR p $70^{\mathrm{S} 6 \mathrm{~K}}$ pathway was determined by immunoblotting and assessing the retardation of electrophoretic mobility as an index of $\mathrm{p} 70^{\mathrm{S} 6 \mathrm{~K}}$ activity. The more severe the constriction, the greater the activation of $\mathrm{p} 70^{\mathrm{S} 6 \mathrm{~K}}$, supporting the notion of a dose-response relationship between the aortic constriction growth stimulus and activation of the $\mathrm{mTOR} / \mathrm{p} 70^{\mathrm{S} 6 \mathrm{~K}}$ signaling pathway (Fig. 2).

Effects of rapamycin treament on cardiac $p \% 0^{\mathrm{S} 6 \mathrm{~K}} a c$ tivation in vivo. To determine the effect of rapamycin injections on growth we initially conducted pilot studies with limited numbers of rats. The pilot data indicated that maximal growth inhibitory effects were obtained with doses of rapamycin of either 0.75 and $1.5 \mathrm{mg} / \mathrm{kg} /$ day. The effects of rapamycin injections on p70 ${ }^{\mathrm{S} 6 \mathrm{~K}}$ activity were examined by immunoblotting. Robust activation of $\mathrm{p} 70^{\mathrm{S} 6 \mathrm{~K}}$ is observed 30 minutes after aortic constriction and is completely inhibited by rapamycin (Fig. 3A). After 3 days of aortic constriction, the activity of $\mathrm{p} 70^{\mathrm{S} 6 \mathrm{~K}}$ is similar in hearts of shamoperated and aortic-constricted rats, suggesting that the $\mathrm{mTOR} / \mathrm{p} 70^{\mathrm{S} 6 \mathrm{~K}}$ pathway has adapted to the pressure overload stimulus (Fig. 3B). The effects of the daily rapamycin injections are still evident because the levels of $\mathrm{p} 70^{\mathrm{S} 6 \mathrm{~K}}$ activity in both sham-operated and aortic-constricted rats are suppressed compared to their vehicle-treated counterparts. The results of an

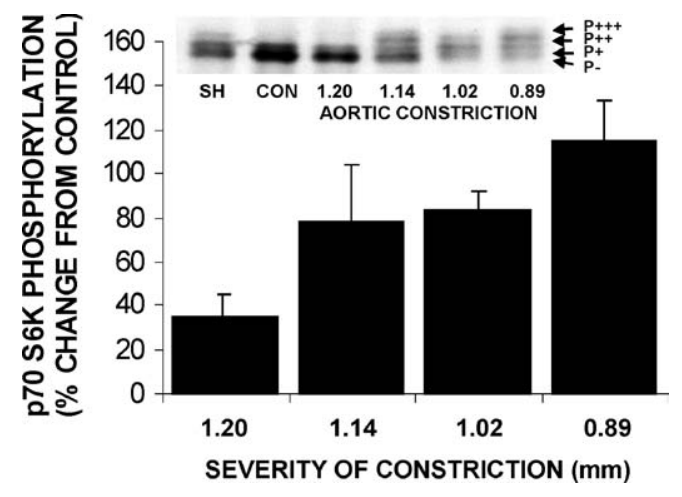

Fig. 2. Dose-response effect of aortic constriction on phosphorylation of $p \% 0$ S6 kinase in rat heart. Left ventricles were harvested 30 minutes after aortic constriction of varying severity was imposed under pentobarbitol anesthesia. Severity of constriction was varied by changing the gap between ends of the hemoclip applicator with a thumbscrew to $1.20 \mathrm{~mm}, 1.14$ $m \mathrm{~m}, 1.02 \mathrm{~mm}, 0.89 \mathrm{~mm}$. Values are mean $\pm S E$ for $n=2$ at each level of severity. Inset: Representative immunoblot where phosphorylation $(P+)$ of p 70 S6 kinase is evident as retarded electrophoretic mobility. There was a significant correlation ( $R$ $=0.53 ; p<0.05)$ between severity of constriction and phosphorylation of pro S6 kinase (Pearson). SH: Sham-operated; CON: control unoperated.

in vitro activity assay of immunoprecipitated $\mathrm{p} 70^{\mathrm{S} 6 \mathrm{~K}}$ from a separate subset of LVs at $30 \mathrm{~min}$ (Fig. 3C) or 3 days (Fig. 3D) post-surgery support a similar conclusion. These data indicate that rapamycin treatment effectively disabled the mTOR/p70 $0^{\mathrm{S} 6 \mathrm{~K}}$ signaling pathway for the duration of the experiment. Therefore, any effects of pressure-overload in hearts of rapamycintreated rats are unlikely to be mediated by mTORdependent signaling.

Effects of rapamycin on cardiac hypertrophy in vivo. With evidence that the $\mathrm{p} 70^{\mathrm{S} 6 \mathrm{~K}}$ pathway is activated by $\mathrm{AC}$ in vivo and data demonstrating the effectiveness of rapamycin in inhibiting the activation of $\mathrm{p} 70^{\mathrm{S} 6 \mathrm{~K}}$ by $\mathrm{AC}$, it was feasible to test the hypothesis that the $\mathrm{mTOR} / \mathrm{p} 70^{\mathrm{S} 6 \mathrm{~K}}$ pathway is important in pressure overload-induced hypertrophic growth of the heart. To address this question, sham-operated and aorticconstricted rats were injected once daily with either vehicle or rapamycin $(1.5 \mathrm{mg} / \mathrm{kg} /$ day $)$ beginning the day prior to surgery and continuing for the duration of the experiment. Rapamycin treatment exerted a significant inhibitory effect on the hypertrophic growth of the left ventricle induced by aortic constriction (Tables 1 and 2). The effect of rapamycin appeared to be most pronounced at 2 days after aortic constriction, suggesting that inhibition of the $\mathrm{mTOR} / \mathrm{p} 70^{\mathrm{S} 6 \mathrm{~K}}$ pathway is crucial to the rapid growth response, and leaving open the possibility that other mechanisms of hypertrophic growth may eventually compensate for mTOR/p70 $0^{\mathrm{S} 6 \mathrm{~K}}$ inhibition. There was, however, no statistically significant difference between day 2 and day 3 results for LV dry 


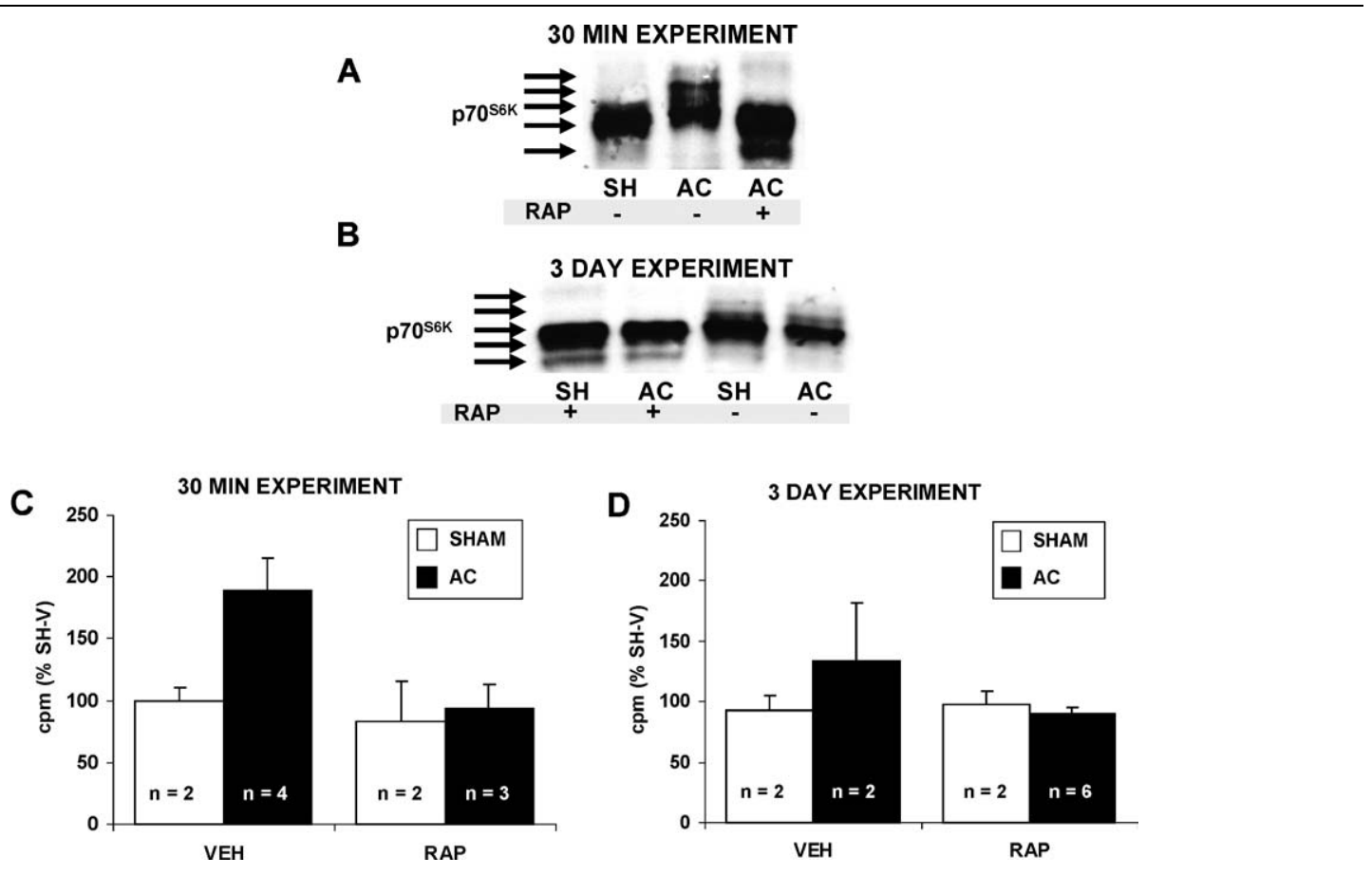

Fig. 3. Inhibition of left ventricular p70 S6 kinase by rapamycin in vivo. Left ventricles were harvested either 30 minutes (A) or 3 days (B) after aortic constriction $(A C)$ or sham-operation $(S H)$. Rats were treated with either $1.5 \mathrm{mg} / \mathrm{kg}$ rapamycin or vehicle beginning 1 day prior to surgery. Phosphorylation state of p 70 S6 kinase is evident in the relative electrophoretic mobility of the immunoreactive bands. Immunoblots shown in panels $A$ and $B$ are single experiments $(n=1)$. In a separate cohort of rats, an in vitro assay of p70 $S 6$ kinase activity was performed on $L V$ tissue harvested at 30 min $(C)$ or 3 days $(D)$ after aortic constriction. Values are mean $\pm S E$ for $n$ =2-6 samples per group. Open bars represent $\mathrm{SH}$; filled bars represent $A C$.

weight. The LV dry weight data presented in Tables 1 and 2 is arguably the most accurate index of tissue hypertrophy. Assessment of hypertrophic growth, however, is more complex when body weight and hydration may be fluctuating. To prevent misinterpretation of hypertrophic growth, body weight was monitored before and after drug and surgical treatments. Aortic constriction had a small negative effect on body weight, while rapamycin treatment induced a much more pronounced degree of weight loss (Tables 1 and 2). To avoid the confounding effects of the rapamycin induced weight loss, the issue of hypertrophy was examined using several commonly used indices, including normalization of LV wet and dry weights to initial and final body weights (data not shown). Regardless of the index used for cardiac hypertrophy, the conclusion that rapamycin

Table 1. Biometric data after 2 days of aortic constriction or sham operation

\begin{tabular}{lcccllll}
\hline & & & & & & \multicolumn{2}{c}{ Statistics } \\
\cline { 5 - 7 }$n$ & SH-VEH & AC-VEH & SH-RAP & AC-RAP & & RAP & AC*RAP \\
\hline IBW (g) & $298 \pm 4$ & $299 \pm 5$ & $288 \pm 5$ & $286 \pm 3$ & NS & $P<0.01$ & NS \\
FBW (g) & $302 \pm 2$ & $300 \pm 6$ & $272 \pm 5$ & $274 \pm 4$ & NS & $P<0.001$ & NS \\
Change in BW (g) & $4 \pm 2$ & $1 \pm 3$ & $-16 \pm 7$ & $-12 \pm 2$ & $P<0.05$ & $P<0.001$ & NS \\
LV wet weight (mg) & $622 \pm 15$ & $758 \pm 16$ & $583 \pm 9$ & $654 \pm 17$ & $P<0.001$ & $P<0.01$ & NS \\
LV D/W Ratio & $22.2 \pm 0.3$ & $21.7 \pm 0.3$ & $23.7 \pm 0.3$ & $21.6 \pm 0.4$ & $P<0.05$ & NS & NS \\
LV dry weight (mg) & $138 \pm 4$ & $164 \pm 2$ & $138 \pm 2$ & $141 \pm 5$ & $P<0.001$ & NS & $P<0.05$ \\
\hline
\end{tabular}

Values are mean \pm SE. Data for all variables in Table 1 were examined using a 3-factor ANOVA procedure, that examined the effects of rapamycin, aortic constriction, number of days after aortic constriction, and interactions between these factors. IBW: initial body weight; FBW: final body weight; LV: left ventricle; D/W: dry weight/wet weight ratio of the LV; AC: main effect of aortic constriction; RAP: main effect of rapamycin treatment; AC*RAP: interaction between AC and RAP. 
Table 2. Biometric data after 3 days of aortic constriction or sham operation

\begin{tabular}{|c|c|c|c|c|c|c|c|}
\hline \multirow[b]{2}{*}{$n$} & \multirow{2}{*}{$\begin{array}{l}\text { SH-VEH } \\
7\end{array}$} & \multirow{2}{*}{$\begin{array}{l}\text { AC-VEH } \\
11\end{array}$} & \multirow{2}{*}{$\begin{array}{l}\text { SH-RAP } \\
5\end{array}$} & \multirow{2}{*}{$\begin{array}{l}\text { AC-RAP } \\
8\end{array}$} & \multicolumn{3}{|c|}{ Statistics } \\
\hline & & & & & $\mathrm{AC}$ & RAP & AC*RAP \\
\hline IBW (g) & $303 \pm 6$ & $303 \pm 4$ & $298 \pm 6$ & $293 \pm 3$ & NS & $P<0.01$ & NS \\
\hline FBW (g) & $307 \pm 6$ & $297 \pm 6$ & $289 \pm 6$ & $272 \pm 3$ & NS & $P<0.001$ & NS \\
\hline Change in BW (g) & $4 \pm 3$ & $-6 \pm 3$ & $-9 \pm 4$ & $-21 \pm 2$ & $P<0.05$ & $P<0.001$ & NS \\
\hline LV wet weight (mg) & $603 \pm 19$ & $800 \pm 27$ & $597 \pm 14$ & $753 \pm 37$ & $P<0.001$ & $P<0.01$ & NS \\
\hline LV D/W Ratio & $22.1 \pm 0.7$ & $21.6 \pm 0.5$ & $23.2 \pm 1.3$ & $21.1 \pm 0.6$ & $P<0.01$ & NS & NS \\
\hline LV dry weight (mg) & $136 \pm 6$ & $172 \pm 6$ & $138 \pm 7$ & $158 \pm 8$ & $P<0.001$ & NS & $P<0.05$ \\
\hline$n$ & 4 & 8 & 4 & 7 & & & \\
\hline RNA ( $\mu \mathrm{g} / \mathrm{g}$ dry wt) & $3157 \pm 300$ & $5097 \pm 327$ & $4267 \pm 528$ & $4838 \pm 278$ & $P<0.01$ & NS & NS \\
\hline RNA ( $\mu \mathrm{g} / \mathrm{g}$ wet wt) & $722 \pm 87$ & $1103 \pm 73$ & $947 \pm 57$ & $1006 \pm 35$ & $P<0.01$ & NS & $P<0.05$ \\
\hline
\end{tabular}

Values are mean \pm SE. Data for all variables in Table 2 (except RNA) were examined using a 3-factor ANOVA procedure, that examined the effects of rapamycin, aortic constriction, number of days after aortic constriction, and interactions between these factors. RNA data were only measured from the 3-day group and were therefore analyzed using a 2-factor ANOVA procedure. IBW: initial body weight; FBW: final body weight; LV: left ventricle; D/W: dry weight/wet weight ratio of the LV; AC: main effect of aortic constriction; RAP: main effect of rapamycin treatment; AC*RAP: interaction between AC and RAP.

attenuated cardiac growth in response to pressure overload is supported. Taken together the data clearly demonstrate that a functional $\mathrm{mTOR} / \mathrm{p} 70^{\mathrm{S} 6 \mathrm{~K}}$ signaling pathway is required for rapid and optimal hypertrophic growth of the heart in response to pressure overload.

Effects of rapamycin on RNA yield. To determine whether rapamycin would influence the accumulation of ribosomal RNA in response to pressure overload, the yield of total RNA per gram of heart tissue was measured. In vehicle-treated rats, the concentration of total RNA in the LV was 53\% greater in the 3 day post-aortic constriction group compared with the sham-operated group (Table 2). In contrast, the concentration of total RNA in the LV of rapamycin-treated rats was only $6 \%$ greater than that of the corresponding sham-operated group. Of note, is the observation that rapamycin-treated sham-operated rats exhibited a $31 \%$ greater concentration of RNA than their vehicletreated counterparts. This finding in vehicle-treated rats is unexpected based on the current understanding of the effects of rapamycin and is not readily explicable. It should be noted that the increase in RNA content in the SH-RAP group compared to the SHVEH group is not statistically significant. It is, however, intriguing, and in the opposite direction one would predict. We have no adequate explanation for this phenomenon, and know of no data that addresses it. We speculate that given the crucial nature of heart function, a mechanism may exist to compensate for decreased RNA production by increased RNA stability. This would apply specifically to ribosomal RNA stability, since RNA content measurements reflect mostly ribosomal RNA. Nonetheless, the significant attenuation of the aortic constriction-induced increase in RNA concentration is consistent with the conclusion that rapamycin inhibits cardiac hypertrophy. Furthermore, the data suggest that rapamycin acts, in part, by in- hibiting the pressure overload-induced accumulation of ribosomal RNA.

Effects of rapamycin on expression of hypertrophyassociated genes. Previous studies of cultured neonatal rat cardiac myocytes treated with growth-inducing agents demonstrated that whereas rapamycin treatment inhibited $\mathrm{p} 70^{\mathrm{S} 6 \mathrm{~K}}$ activation and hypertrophic growth in tandem, it did not affect the increased expression of c-fos, atrial natriuretic factor (ANF), skeletal $\alpha$-actin, or $\beta$-myosin heavy chain that is normally associated with hypertrophy $[9,10]$. To determine whether this apparent dissociation of transcriptional and translational regulation extended to the in vivo situation, total RNA was isolated from hearts of each of the 4 groups of rats and subjected to RNA blotting. Three days of aortic constriction increased the expression of ANF and skeletal $\alpha$-actin mRNA by approximately 2 -fold. The aortic constriction-induced increases in ANF and skeletal $\alpha$-actin mRNA were not significantly diminished by rapamycin treatment (Fig. 4). Thus, a dissociation between the expression of two hypertrophy-associated genes and hypertrophic growth was observed in the intact heart in vivo, and is consistent with the observations made previously in cultured neonatal rat cardiac myocytes $[9,10]$. In contrast, the effects of rapamycin on myosin heavy chain mRNA levels were striking. Compared to hearts of vehicle treated rats, those of rapamycin treated rats exhibited a 3 -fold increase in the levels of $\alpha$-MHC mRNA (Fig. 5). Whereas the levels of $\alpha$-MHC mRNA were unaffected by aortic constriction in the hearts of vehicle-treated rats, they were markedly decreased in the hearts of rapamycintreated rats. Rapamycin treatment produced a 6 -fold increase in the levels of $\beta$-MHC mRNA relative to vehicle treatment. Aortic constriction increased levels of $\beta$-MHC mRNA in hearts of vehicle-treated rats, but it had no effect in hearts of rapamycin-treated rats. While rapamycin and aortic constriction both induced 
A
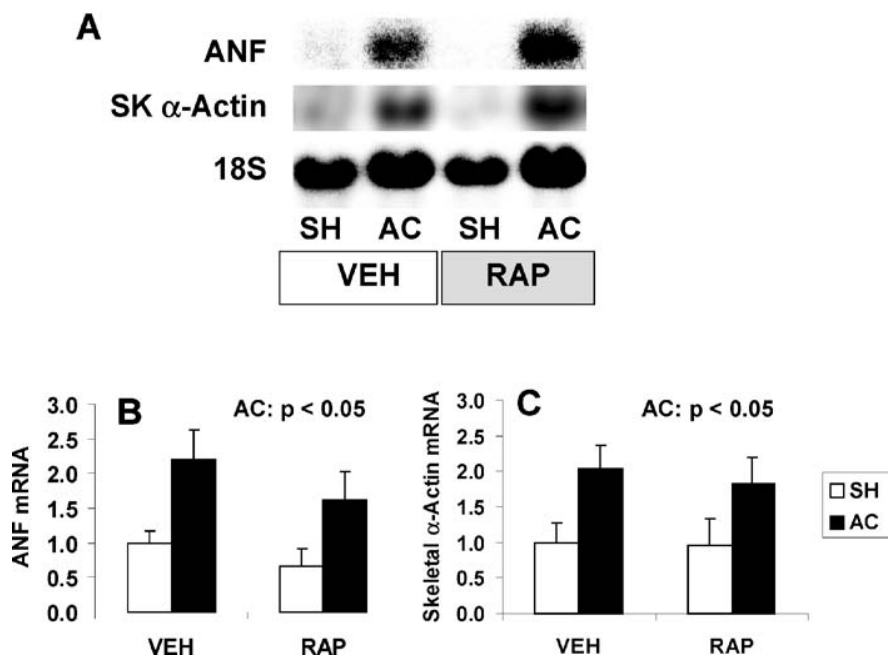

Fig. 4. Effects of rapamycin treatment and aortic constriction on expression of atrial natriuretic factor (ANF) and skeletal (SK) $\alpha$-actin mRNA. Left ventricles were harvested 3 days after aortic constriction (AC) or sham-operation (SH). Rats were treated with rapamycin (RAP) or carboxymethylcellulose vehicle (VEH) beginning 1 day prior to surgery. Total RNA was harvested and prepared for Northern blotting as described in Methods. Messenger RNA levels are expressed relative to 18S ribosomal RNA, and then adjusted for the yield of total RNA per gram tissue (see Table 2), so that they represent the relative amount of RNA per gram dry tissue weight. A significant main effect of aortic constriction was observed and there were no main or interactive effects of rapamycin (2-factor ANOVA). Values are mean $\pm S E$ for $n=4,8$, 4, and 7 in $S H$-VEH, AC-VEH, SH-RAP, and the AC-RAP groups, respectively.

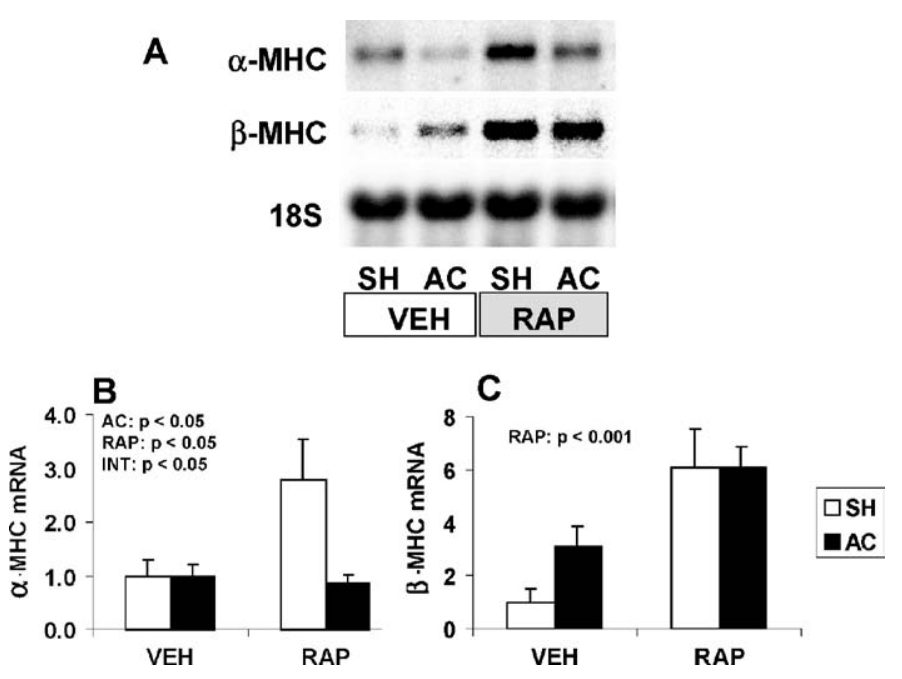

Fig. 5. Effects of rapamycin treatment and aortic constriction on expression of $\alpha$-and $\beta$-myosin heavy chain (MHC) $m R N A$. Left ventricles were harvested 3 days after aortic constriction $(A C)$ or sham-operation (SH). Rats were treated with rapamycin (RAP) or carboxymethylcellulose vehicle (VEH) beginning 1 day prior to surgery. Total RNA was harvested and prepared for Northern blotting as described in Methods. Messenger RNA levels are expressed relative to $18 \mathrm{~S}$ ribosomal RNA, and then adjusted for the yield of total $R N A$ per gram tissue (see Table 2), so that they represent the relative amount of RNA per gram dry tissue weight. For $\alpha-M H C$, significant main effects of aortic constriction and rapamycin were observed, as well as an interaction (INT) between the effects of aortic constriction and rapamycin (2-factor ANOVA). For $\beta$-MHC, only a significant main effect of rapamycin was observed (2-factor ANOVA). Values are mean $\pm S E$ for $n=4,8$, 4, and 7 in $S H-V E H, A C-V E H, S H-R A P$, and the AC-RAP groups, respectively.

increases in the levels of $\beta$-MHC, rapamycin alone had a more potent effect on $\beta$-MHC expression than did pressure overload alone. Furthermore, the effects of rapamycin on $\beta$-MHC expression were not additive when rats were subjected to both aortic constriction and rapamycin treatment. The effects of rapamycin on expression of the myosin heavy chain mRNA levels suggest a link between the mTOR/ $\mathrm{p} 70^{\mathrm{S} 6 \mathrm{~K}}$ signaling 
Table 3. Effects of rapamycin treatment and aortic constriction on gene expression

\begin{tabular}{|c|c|c|c|c|c|c|c|}
\hline \multirow[b]{2}{*}{$n$} & \multirow{2}{*}{$\begin{array}{l}\text { SH-VEH } \\
4\end{array}$} & \multirow{2}{*}{$\begin{array}{l}\mathrm{AC}-\mathrm{VEH} \\
8\end{array}$} & \multirow{2}{*}{$\begin{array}{l}\text { SH-RAP } \\
4\end{array}$} & \multirow{2}{*}{$\begin{array}{l}\text { AC-RAP } \\
7\end{array}$} & \multicolumn{3}{|c|}{ Statistics } \\
\hline & & & & & $\mathrm{AC}$ & RAP & $\mathrm{AC}^{*} \mathrm{RAP}$ \\
\hline$\beta$-Actin & $1.00 \pm 0.18$ & $2.83 \pm 0.45$ & $1.55 \pm 0.23$ & $2.37 \pm 0.27$ & $P<0.01$ & NS & NS \\
\hline Cardiac $\alpha$-Actin (CA) & $1.00 \pm 0.14$ & $1.25 \pm 0.26$ & $1.09 \pm 0.28$ & $1.02 \pm 0.11$ & $\mathrm{NS}$ & NS & NS \\
\hline Collagen Type I & $1.00 \pm 0.07$ & $1.71 \pm 0.20$ & $1.42 \pm 0.30$ & $1.46 \pm 0.12$ & NS & NS & NS \\
\hline Fibronectin $(\mathrm{FN})$ & $1.00 \pm 0.30$ & $1.82 \pm 0.19$ & $1.37 \pm 0.27$ & $1.57 \pm 0.13$ & $P<0.05$ & NS & NS \\
\hline $\begin{array}{c}\text { Glyceraldehyde-3-Phosphate } \\
\text { dehydrogenase (GAPDH) }\end{array}$ & $1.00 \pm 0.15$ & $0.95 \pm 0.11$ & $1.63 \pm 0.36$ & $0.98 \pm 0.02$ & $P<0.05$ & NS & NS \\
\hline Preproenkephalin (PNK) & $1.00 \pm 0.06$ & $0.60 \pm 0.14$ & $1.07 \pm 0.20$ & $0.64 \pm 0.11$ & $P<0.05$ & NS & NS \\
\hline
\end{tabular}

pathway and the regulation of myosin heavy chain gene expression in the rat heart.

To determine whether other hypertrophyassociated genes are influenced by rapamycin, we performed Northern blots for fibronectin, collagen Type I, and preproenkephalin as well as several reference or housekeeping genes (Table 3). While each of the above-mentioned genes exhibited changes in expression in the expected direction in response to pressure-overload, no significant effects of rapamycin were observed. The lack of a rapamycin effect on the expression of a number of genes that represent several different gene families suggests that the effects of rapamycin on gene expression are at least somewhat selective.

Effect of rapamycin on $\beta$-MHC promoter activity. To determine the possible effects of rapamycin on transcription, we transfected neonatal cardiac myocytes with a $\beta$-MHC promoter-luciferase reporter construct and treated the cells with vehicle or rapamycin. Relative to the co-transfected CMV-renilla activity, rapamycin increased the luciferase activity by approximately 2 -fold (Fig. 6). We speculate that mTOR signaling may mildly suppress $\beta$-MHC promoter activity and that inhibition of mTOR with rapamycin may relieve the mTOR-mediated suppression. Alternatively, rapamycin may stimulate $\beta$-MHC promoter activity by an mTOR-independent means.

\section{Discussion}

Previous studies have demonstrated that the $\mathrm{mTOR} / \mathrm{p} 70^{\mathrm{S} 6 \mathrm{~K}}$ signaling pathway is required for a robust hypertrophic growth response in cardiac myocytes induced by angiotensin II [9] or phenylephrine [10]. Growth of the heart in vivo, however, is a much more complex process, and the importance of this pathway to hypertrophy of the intact rat heart in vivo had not been reported when the present study was initiated. The present study demonstrates that the $\mathrm{mTOR} / \mathrm{p} 70^{\mathrm{S} 6 \mathrm{~K}}$ signaling pathway is required for the normal growth response of the heart to pressure overload. The data are consistent with the notion that cardiac hypertrophy in vivo involves coordinate upregulation of both transcriptional and translational processes. The findings corroborate and extend previous reports in which rapamycin inhibited cardiac hypertrophy in cultured cardiac myocytes [9,10,32,33]. Unexpectedly, the present data also suggest a novel link between the mTOR/ $\mathrm{p} 70^{\mathrm{S} 6 \mathrm{~K}}$ signaling pathway and the expression of the functionally critical myosin heavy chain genes in the heart.

A growing number of upstream growth signals have been identified that activate mTOR, including insulin, various G-protein-coupled receptors, and nutrients $[7,9,10,15,32,33]$. Downstream, mTOR activates the S6 kinases S6K1 and S6K2 and phosphorylates
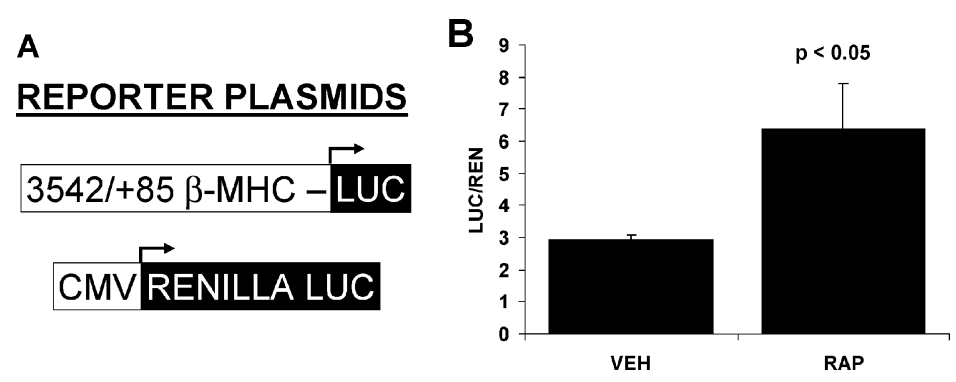

Fig. 6. Regulation of $\beta$-myosin heavy chain promoter activity by rapamycin. Neonatal rat cardiac myocytes were transfected with the indicated plasmids and treated for 48 hours with vehicle (ethanol) or rapamycin. Signals were quantified with a dual luciferase assay. LUC, luciferase; REN, renilla luciferase; VEH, vehicle; $R A P$, rapamycin. Values are mean $\pm S E$ for $n=4$ experiments. $p<0.05, t$-test. 
4E-BP1 in parallel [15]. S6K1 is primarily, but not exclusively, cytosolic, phosphorylating the ribosomal S6 protein and thereby modifying translational dynamics. The S6K1 homologue S6K2, on the other hand, localizes mostly in the nucleus, with function(s) that have yet to be clarified [34]. Phosphorylation of 4E$\mathrm{BP} 1$ relieves inhibition of the initiation factor eIF4E, a component of the large translation initiation complex, thereby modulating translation [15]. Rapamycin forms a complex with the FK506 binding protein (FKBP) and this complex in turn binds mTOR, thereby inhibiting signals to each of the downstream signaling entities mentioned above [15,34]. In this study, phosphorylation and/or activity of S6K1 was measured to verify that signaling in the heart tissue via mTOR was indeed blocked by rapamycin administered via intraperitoneal injection. The present data do not elucidate relative contributions of S6K1, S6K2, or 4E-BP1, but they support the notion that mTOR signaling is crucial for optimal pressure overload-induced growth of the heart.

The apparent differences between the complete inhibition of growth at day two post-AC and the attenuation of growth at day three, suggest the possibility that the rapamycin blockade of the mTOR/ $\mathrm{p} 70^{\mathrm{S} 6 \mathrm{~K}}$ signaling pathway may merely delay hypertrophy of the heart in vivo. That is, if studied for a longer time, it is possible that the growth of the heart in the presence of rapamycin would eventually "catch up" to that in the vehicle-treated AC rats. This is an important question left unanswered by the present study. A recent study of mice, however, shows that the effects of rapamycin to attenuate aortic constriction-induced cardiac growth are persistent for at least one week [35]. The study by Shioi and coworkers [35] showed for the first time that, in mice subjected to pressure overload for 1 week, rapamycin $(2 \mathrm{mg} / \mathrm{kg} /$ day $)$ markedly attenuated cardiac hypertrophy at the organ and cellular levels. They also demonstrated that rapamycin blocked activation of S6K1 and phosphorylation of its ribosomal S6 target. $\mathrm{LV}$ function and expression of two fetal genes, atrial natriuretic factor (ANF) and brain natiruretic peptide (BNP) were unaffected by rapamycin treatment. The present study confirms the major conclusion of Shioi and coworkers, that rapamycin attenuates pressure overload-induced cardiac hypertrophy, and extends the finding to rats. In agreement with Shioi and coworkers, it was found that rapamycin effectively eliminated aortic constriction-related signaling via mTOR to S6K1. Also in agreement is the present finding that rapamycin did not influence LV expression of ANF in either sham-operated or aortic-constricted rats. One notable difference between the study of Shioi and the present study is that we observed a rather marked effect of rapamycin to induce weight loss in rats. A novel finding of the present study is that rapamycin had marked effects on the expression of both the $\alpha$ - and the $\beta$-myosin heavy chain genes. Taken together, the present study and the study by
Shioi and coworkers [35], indicate that the mTOR/ p $70^{\mathrm{S} 6 \mathrm{~K}}$ signaling pathway is required for the normal growth response of the heart to pressure overload in rodents.

Previous studies of cultured myocytes treated with growth factors $[9,10]$ and of intact mice subjected to pressure overload in vivo [35] demonstrated that despite the inhibitory effects of rapamycin on hypertrophic growth, there was no effect of rapamycin on the induction of so-called fetal genes, such as ANF and skeletal $\alpha$-actin. Data presented here on the expression of ANF is consistent with the previous studies, and suggests that the influence of $\mathrm{mTOR} / \mathrm{p} 70^{\mathrm{S} 6 \mathrm{~K}}$ signal transduction pathway is restricted to regulation of translational events. Thus, the finding that rapamycin had a potent stimulatory effect on the levels of both $\alpha$-MHC and $\beta$-MHC mRNAs, is both surprising and intriguing. It raises important questions about how the $\mathrm{mTOR} / \mathrm{p} 70^{\mathrm{S} 6 \mathrm{~K}}$ pathway exerts influence on the mRNA levels of these vitally important contractile proteins. The influence of rapamycin treatment on the levels of MHC mRNA may be attributed to either increased transcription, or to enhanced mRNA stability. The data presented in Figure 6 suggest that in cultured myocytes transcription of the $\beta$-MHC gene may be increased by rapamycin. Although not as extensively studied as the translational effects of $\mathrm{mTOR} / \mathrm{p} 70^{\mathrm{S} 6 \mathrm{~K}} \mathrm{sig}$ naling, there is evidence to support interaction of elements of the mTOR/p70 ${ }^{\mathrm{S} 6 \mathrm{~K}}$ signaling pathway with nuclear processes. For example, an alternatively spliced variant of the $\mathrm{p} 70^{\mathrm{S} 6 \mathrm{~K}}$ gene, termed $\mathrm{p} 85^{\mathrm{S} 6 \mathrm{~K}}$, has an $\mathrm{N}$ terminal extension that directs it to the nucleus [36]. Moreover, nuclear localization of $\mathrm{p} 85^{\mathrm{S} 6 \mathrm{~K}}$ has been observed in cardiac myocytes undergoing load-induced hypertrophy [11]. Whether or not the influence of rapamycin on $\mathrm{MHC}$ gene expression is mediated by $\mathrm{p} 85^{\mathrm{S} 6 \mathrm{~K}}$ or another member of the mTOR/p70 $\mathrm{s} 6 \mathrm{~K}$ signaling pathway, or is an mTOR-independent effect of rapamycin, remains to be determined. It is notable that the effects of pressure overload and rapamycin on $\beta$ MHC mRNA levels were not additive, yet pressure overload completely reversed the rapamycin-induced increase in the levels of $\alpha$-MHC mRNA. It will be important to determine whether these effects of rapamcyin are mediated via elements in the 5' upstream regions of the MHC genes, such as the GATA element that confers transcriptional activation of the $\beta$-MHC gene by pressure overload in vivo [37].

Several important limitations of the present study should be noted. First, no data were provided on the size changes of individual myocytes, thereby limiting the conclusions to cardiac hypertrophy at the organ level. Second, the conclusions regarding cardiac hypertrophy must be restricted to the rapid growth that normally occurs in response to the first 3 days of pressure overload. The data leave unanswered the question of whether or not the rapamycin-mediated inhibition of hypertrophy is transient or sustained indefinitely. Third, this study did not examine any of 
the upstream or parallel elements of the $\mathrm{mTOR} / \mathrm{p} 70^{\mathrm{S} 6 \mathrm{~K}}$ signal transduction pathway, such as Akt or 4EBP-1, which are likely to be involved.

The data presented here provide evidence that the $\mathrm{mTOR} / \mathrm{p} 70^{\mathrm{S} 6 \mathrm{~K}}$ signal transduction pathway plays a role in the early rapid phase of pressure overload-induced cardiac hypertrophy. Pressure overload activated $\mathrm{p} 70^{\mathrm{S} 6 \mathrm{~K}}$ in the rat heart in a dose-dependent manner. Injection of rapamycin into the peritoneal cavity of rats effectively suppressed basal and pressureoverload-induced activation of $\mathrm{p} 70^{\mathrm{S} 6 \mathrm{~K}}$ in the heart. Cardiac hypertrophy was significantly attenuated in rapamycin-treated rats, suggesting that an intact rapamycin-sensitive mTOR signal transduction pathway is required for a normal growth response to pressure overload in the rat heart in vivo. While the pressure overload-induced increase in expression of the ANF gene was unaffected by rapamycin treatment, the levels of $\alpha$ - and $\beta$-MHC mRNA were markedly influenced by rapamycin, suggesting a novel link between the mTOR signal transduction pathway and transcriptional activity in cardiac myocytes. Since rapamycin is used clinically as an immunosuppressant [38], these findings may have important implications for transplant patients with compromised heart function. Moreover, the potential therapeutic value of cardiac hypertrophy inhibition by agents such as rapamycin has recently been suggested [39].

\section{Acknowledgments}

The authors are grateful to Wyeth-Ayerst for providing the rapamycin used in these experiments, and to Keith Baar for critical reading of the manuscript. Support was provided by the Michigan and Midwest Affiliates of the American Heart Association.

\section{References}

1. Sugden PH, Clerk A. Cellular mechanisms of cardiac hypertrophy. J Mol Med 1998;76:725-746.

2. Cooper G 4th. Basic determinants of myocardial hypertrophy: A review of molecular mechanisms. Annu Rev Med 1997;48:13-23.

3. Morgan HE, Gordon EE, Kira Y, et al. Biochemical mechanisms of cardiac hypertrophy. Annu Rev Physiol 1987;49:533-543.

4. Zak R, Rabinowitz M. Molecular aspects of cardiac hypertrophy. Annu Rev Physiol 1979;41:539-552.

5. Kozma S, Thomas G. Regulation of cell size in growth, development and human disease: PI3K, PKB and S6K. Bioessays 2002;24:65-71.

6. Montagne J, Stewart MJ, Stocker H, Hafen E, Kozma SC, Thomas G. Drosophila S6 kinase: A regulator of cell size. Science 1999;285:2126-2129.

7. Baar K, Esser K. Phosphorylation of p70S6k correlates with increased skeletal muscle mass following resistance exercise. Am J Physiol 1999;276:C120-C127.

8. Bodine SC, Stitt TN, Gonzalez M, et al. Akt/mTOR pathway is a crucial regulator of skeletal muscle hypertrophy and can prevent muscle atrophy in vivo. Nat Cell Biol 2001;3:10141019.

9. Sadoshima J, Izumo S. Rapamycin selectively inhibits angiotensin induced increase in protein synthesis in cardiac myocytes in vitro: Potential role of $70-\mathrm{kD}$ S6 kinase in angiotensin-induced cardiac hypertrophy. Circ Res 1995;77:1040-1052.

10. Boluyt MO, Zheng JS, Younes A, et al. Rapamycin inhibits $\alpha_{1}$-adrenergic receptor-stimulated cardiac myocyte hypertrophy but not activation of hypertrophy-associated genes: Evidence for involvement of p70 S6 kinase. Circ Res 1997;81:176-186.

11. Laser M, Kasi VS, Hamawaki M, Cooper IV G, Kerr CM, Kuppuswamy D. Differential activation of p70 and p85 S6 kinase isoforms during cardiac hypertrophy in the adult mammal. J Biol Chem 1998;273:24610-24619.

12. Nygard O, Nilsson L. Translational dynamics: Interactions between the translational factors, tRNA, and ribosomes during eukaryotic protein synthesis. Eur J Biochem 1990;191:117.

13. Jeffries HJB, Reinhard C, Kozma SC, Thomas G. Rapamycin selectively represses translation of the "polypyrimidine tract” mRNA family. Proc Natl Acad Sci USA 1994;91:44414445.

14. Chung J, Kuo CJ, Crabtree GR, Blenis J. Rapamycin-FKBP specifically blocks growth-dependent activation of and signaling by the 70 kd S6 protein kinases. Cell 1992;69:12271236.

15. Brown EJ, Schreiber SL. A signaling pathway to translational control. Cell 1996;86:517-520.

16. Nourse J, Firpo E, Flanagan WM, et al. Interleukin-2mediated elimination of the $\mathrm{p} 27^{\mathrm{KIP} 1}$ cyclin-dependent kinase inhibitor prevented by rapamycin. Nature 1994;372:570573.

17. Schreiber SL. Chemistry and biology of the immunophilins and their immunosuppressive ligands. Science 1991;251:283287.

18. Chang JY, Sehgal SN, Bansbach CC. FK506 and rapamycin: Novel pharmacological probes of the immune response. Trends Pharmacol Sci 1991;12:218-223.

19. Kunz J, Hall MN. Cyclosporin A, FK506 and rapamycin: More than just immunosuppression. Trend Biochem Sci 1993;18:334-338.

20. Levy S, Avni D, Hariharan N, Perry RP, Meyuhas O. Oligopyrimidine tract at the 5' end of mammalian ribosomal protein mRNAs is required for their translational control. Proc Natl Acad Sci USA 1991;88:3319-3323.

21. Terada N, Patel HR, Takase K, Kohno K, Nairn AC, Gelfand EW. Rapamycin selectively inhibits translation of mRNAs encoding elongation factors and ribosomal proteins. Proc Natl Acad Sci USA 1994;91:11477-11481.

22. Siehl D, Chua BHL, Lautensack-Belser N, Morgan HE. Faster protein and ribosome synthesis in thyroxine-induced hypertrophy of rat heart. Am J Physiol 1985;248:C309_ C319.

23. Bishopric NH, Simpson PC, Ordahl CP. Induction of the skeletal $\alpha$-actin gene in $\alpha_{1}$-adrenoceptor-mediated hypertrophy of rat cardiac myocytes. J Clin Invest 1987;80:1194-1199.

24. Boluyt MO, Opiteck JA, Esser KE, White TP. Cardiac adaptations to aortic constriction in adult and aged rats. $\mathrm{Am} \mathrm{J}$ Physiol 1989;257:H643-H648.

25. Boluyt MO, O’Neill L, Meredith AL, et al. Alterations in cardiac gene expression during the transition from stable hypertrophy to heart failure. Marked upregulation of 
genes encoding extracellular matrix components. Circ Res 1994;75:23-32.

26. Zheng JS, Boluyt MO, O'Neill L, Crow MT, Lakatta EG. Extracellular ATP induces immediate-early gene expression but not cellular hypertrophy in neonatal cardiac myocytes. Circ Res 1994;74:1034-1041.

27. Blake MJ, Fargnoli J, Gershon D, Holbrook NJ. Concomitant decline in heat-induced hyperthermia and HSP70 mRNA expression in aged rats. Am J Physiol 1991;260:R663R667.

28. Long X, Crow MT, Sollott SJ, et al. Enhanced expression of p53 and apoptosis induced by blockade of the vacuolar proton ATPase in cardiomyocytes. J Clin Invest 1998;101:14531461.

29. Izumo S, Nadal-Ginard B, Mahdavi V. Protooncogene induction and reprogramming of cardiac gene expression produced by pressure overload. Proc Natl Acad Sci USA 1988;85:339-343.

30. Chien KR, Knowlton KU, Zhu H, Chien AS. Regulation of cardiac gene expression during myocardial growth and hypertrophy: Molecular studies of an adaptive physiologic response. FASEB J 1991;5:3037-3046.

31. Schneider MD, Packer SE, Parker TG. Peptide growth factors can provoke "fetal" contractile protein gene expression in rat cardiac myocytes. J Clin Invest 1990;85:507-514.

32. Baliga RR, Pimental DR, Zhao YY, et al. NRG-1-induced cardiomyocyte hypertrophy. Role of PI-3-kinase, p70(S6K), and MEK-MAPK-RSK. Am J Physiol 1999;277:H2026H2037.

33. Simm A, Schluter K, Diez C, Piper HM, Hoppe J. Activation of $\mathrm{p} 70(\mathrm{~S} 6)$ kinase by beta-adrenoceptor agonists on adult cardiomyocytes. J Mol Cell Cardiol 1998;30:20592067.

34. Park IH, Bachmann R, Shirazi H, Chen J. Regulation of ribosomal S6 kinase 2 by mammalian target of rapamycin. $J$ Biol Chem 2002;277:31423-429.

35. Shioi T, McMullen JR, Tarnavski O, et al. Rapamycin attenuates load-induced cardiac hypertrophy in mice. Circulation 2003;107:1664-1670.

36. deGroot RP, Ballou LM, Sassone Corsi P. Positive regulation of the cAMP-responsive activator CREM by the p70 S6 kinase: An alternative route to mitogen-induced gene expression. Cell 1994;79:81-91.

37. Hasegawa K, Lee SJ, Jobe SM, Markham BE, Kitsis RN. cis-Acting sequences that mediate induction of beta-myosin heavy chain gene expression during left ventricular hypertrophy due to aortic constriction. Circulation 1997;96:39433953.

38. Saunders RN, Metcalfe MS, Nicholson ML. Rapamycin in transplantation: A review of the evidence. Kidney Int 2001;59:3-16.

39. Frey N, Katus HA, Olson EN, Hill JA. Hypertrophy of the heart: A new therapeutic target? Circulation 2004;109:15801589 . 